\title{
Accuracy of an automatic analysis software to detect microvascular density parameters
}

\author{
A Carsetti ${ }^{1,2^{*}}$, S Pierantozzi ${ }^{1,2}$, HD Aya ${ }^{2,3}$, S Bazurro ${ }^{2}$, A Donati $^{1}$, A Rhodes $^{2,3}$, M Cecconi $^{2,3}$ \\ From ESICM LIVES 2015 \\ Berlin, Germany. 3-7 October 2015
}

\section{Introduction}

Analysis of microvascular density parameters is time consuming and operator-dependent. ${ }^{1}$ This is the main limitation to use microvascular monitoring in clinical practice as a "point-of-care" tool. Recently, an automatic analysis software has been developed and could allow us to obtain results quickly.

\section{Objectives}

The aim of this study was to assess the accuracy of microvascular density parameters (total vessel density (TVD), perfused vessel density (PVD) and proportion of perfused vessels (PPV)) obtained by the new automatic analysis software CytoCamTools 1.7.12 (CC) (Braedius, Amsterdam, The Netherlands) in comparison with Automated Vascular Analysis (AVA) software 3.2 (MicroVision Medical, Amsterdam, The Netherlands).

\section{Methods}

Sublingual microcirculatory videos were obtained using an incidence dark field-imaging device (CytoCam, Braedius, Amsterdam, The Netherlands). Only videos with a high quality score ${ }^{2}$ were selected for the analysis. Each video was analysed using AVA 3.2 by two skilled operators and results were compared with the analysis obtained by the CytoCamTools 1.7.12 software. Bland-Altman analysis was used to look at the agreement between the automatic software and the operators.

\section{Results}

84 videos from 22 patients after cardiac surgery were analysed. The mean bias between TVD-CC and TVD-AVA was $2.17 \mathrm{~mm} / \mathrm{mm}^{\wedge} 2(95 \%$ CI 1.44 to $2.90 ; \mathrm{p}=0.0001)$ with limits of agreement (LOA) of -4.41 (95\% CI -5.66 to
-3.16) and 8.76 (95\% CI 7.50 to 10.01$) \mathrm{mm} / \mathrm{mm}^{\wedge} 2$ (Figure 1). The mean bias between PVD-CC and PVDAVA was $6.54 \mathrm{~mm} / \mathrm{mm}^{\wedge} 2(95 \%$ CI 5.67 to $7.42 ; \mathrm{p} 0.0001)$ with LOA of -1.37 (95\% CI -2.87 to 0.13 ) and $14.46(95 \%$ CI 12.95 to 15.96$) \mathrm{mm} / \mathrm{mm}^{\wedge} 2$ (Figure 2). A good correlation was found between the average of PPV-CC and PPVAVA and the difference of the two measurements where $\triangle \mathrm{PPV}=-1.85$ (mean PPV) $+181(\mathrm{R}=-0.94,(95 \% \mathrm{CI}-0.96$ to $-0.91 ; \mathrm{p}<0.0001)$.

\section{Conclusions}

This study shows acceptable bias but wide limits of agreement for the comparison of TVD, PVD and PPV between the automated $\mathrm{CC}$ system and skilled operators. Further software improvements may be needed before real time point of care testing of the microcirculation can be used at the bedside.

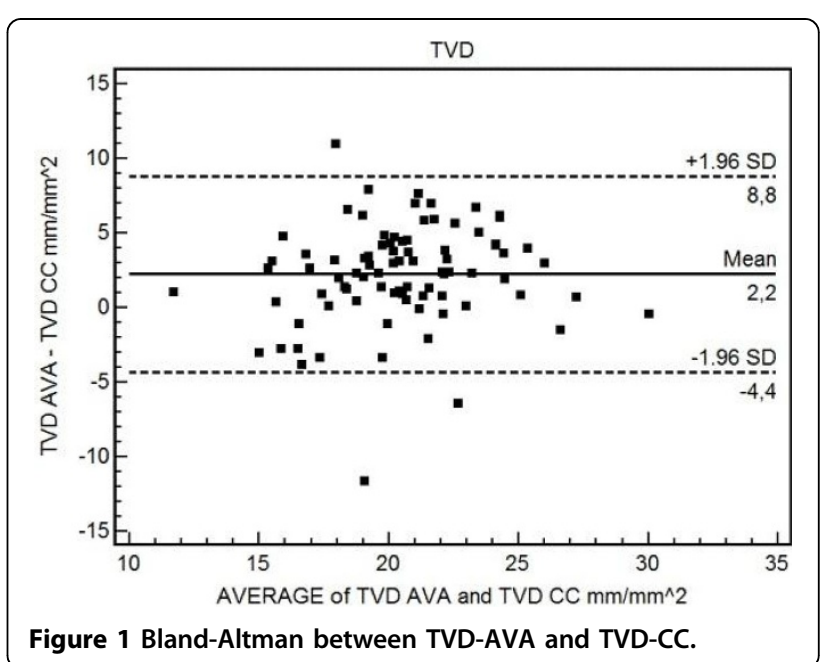




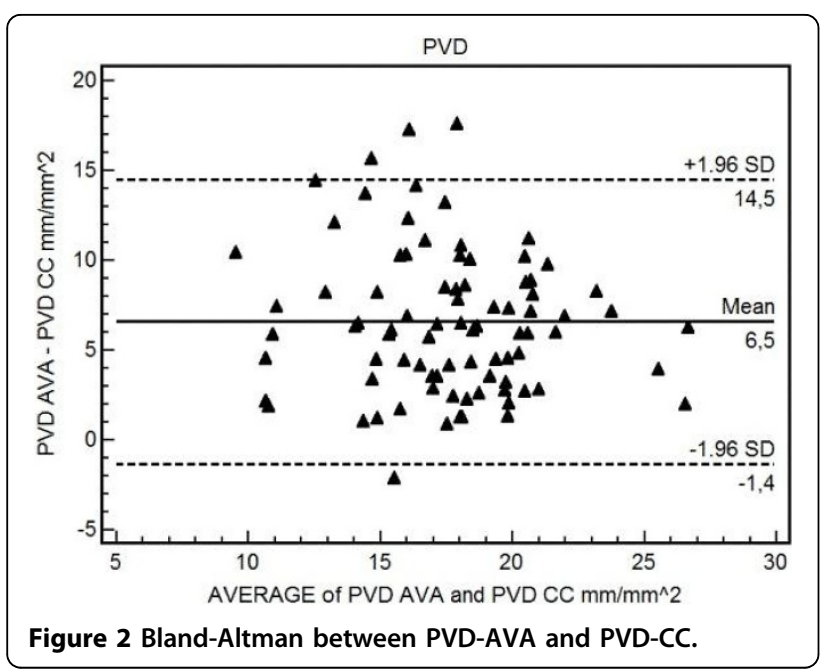

\section{Authors' details}

'Università Politecnica delle Marche, Department of Biomedical Sciences and Public Health, Ancona, Italy. ${ }^{2}$ St George's University Hospitals NHS Foundation Trust, Department of Intensive Care Medicine, London, United Kingdom. ${ }^{3}$ St George's University of London, London, United Kingdom.

Published: 1 October 2015

\section{References}

1. De Backer D, Hollenberg S, Boerma C, Goedhart P, Büchele G, OspinaTascon $G$, et al: How to evaluate the microcirculation: report of a round table conference. Crit Care 2007, 11(5):R101.

2. Massey MJ, Larochelle E, Najarro G, Karmacharla A, Arnold R, Trzeciak S, et al: The microcirculation image quality score: development and preliminary evaluation of a proposed approach to grading quality of image acquisition for bedside videomicroscopy. J Crit Care 2013, 28(6):913-917.

doi:10.1186/2197-425X-3-S1-A415

Cite this article as: Carsetti et al: Accuracy of an automatic analysis software to detect microvascular density parameters. Intensive Care Medicine Experimental 2015 3(Suppl 1):A415.

\section{Submit your manuscript to a SpringerOpen ${ }^{\mathcal{O}}$ journal and benefit from:}

- Convenient online submission

- Rigorous peer review

- Immediate publication on acceptance

- Open access: articles freely available online

- High visibility within the field

- Retaining the copyright to your article 